\title{
A BRIEF HISTORY OF METROPOLITAN PLANNING IN MELBOURNE, AUSTRALIA
}

Jun Tsutsumi

Ray Wyatt

This issue considerably extends the scope of Applied GIS. Whereas in previous issues the technicalities of GIS and remote sensing tended to dominate, we here take our first step towards more synoptic and policy-advising components of GIS application. In no way do we intend to forsake the detailed topic areas which have served us so well in the past; we merely want to add something else to them. Accordingly, volume 2 number 2 contains a little of the old and a large chunk of the new.

The latter takes the form of a special collection of theme papers on GIS-based analyses of urban land use and activity patterns within the Australian city of Melbourne and elsewhere always with an eye on the policy implications that such investigations invariably prompt. With the final edition of 2006, 2 (3), also planned to be a special theme issue, but one which focuses on GIS-oriented decision support for improved rural management, by the end of the year we will have fully completed our rounding out of Applied GIS' range.

In other words, by 2007 the ambit of Applied GIS will extend all the way from detailed remote sensing and spatial analysis, through decision support for managing the natural environment to urban morphology and planning. This will advantageously position our journal for attracting a large number of high-quality papers from across the complete spectrum of applied GIS.

To usher in such expansion, the bulk of this editorial will contextualize the papers that are part of the urban morphology theme. This should enable readers to better appreciate and understand them. Nevertheless, we will begin by introducing the other two, non-theme papers that have made it through Applied GIS's refereeing system independently of the theme issue.

\section{THE NON-THEME PAPERS}

The first of these, Brian Lees' contribution towards better interpretation of spectral data, continues this journal's growing tradition of excellence. It describes work that surely sits at the research frontier. It exploits an innovative statistical method to extract hidden information from images rather than rely on the more traditional, but frequently error-prone conversion of interval to nominal data.

The second of our "normal” papers also extends Applied GIS's tradition of rigorous spatial analysis, although this time within the context of the highly urbanized state of Singapore. By measuring spatial proximity in ways that are only practical using modern GIS, and by interviewing no less than 5000 people to find out what sort of facilities they would like to be close to, this paper deduces which Singaporean suburbs are likely to be in demand as locations for new public housing in the future.

\section{THE THEME PAPERS}

Four out of the five theme papers were actually written by Japanese scholars. As such, their writings could shake some Melbournians out of their complacency that stems from satisfaction 
with a high-quality, urban environment. Yet on the other hand, outside researchers sometimes miss the true essence of Melbourne's history, character and current management. Accordingly, this editorial has been written by two people, one being a Japanese urban geographer who has visited Melbourne no less than nine times, and the other being a local researcher who has adopted Melbourne as his home town.

Melbourne is a sprawling metropolis of 3.6 million people which is aesthetically pleasing, popular with tourists, commercially important, comfortable, nurturing and a leader in higher education, medical research, entertainment, shopping and multi-cultural cuisine. Nevertheless, some commentators have agonized over its physical environment, which they say is deteriorating. This is despite Melbourne's "quality of life" index having been judged in 1990, by a UN committee, to be the world's highest, and it has remained amongst the leaders ever since. Hence if nothing else, Melbourne's amenity has shown considerable resistance to the forces pulling it downwards towards the environmental depths plumbed by less attractive world cities.

One of the keys to such resilience is the history of Melbourne's metropolitan planning, which we will examine here on the basis that one needs to look backwards to see where a city is currently positioned, as well as the direction in which it could go in the future. We will then highlight some of the insights provided by the theme papers, along with some of their policy-relevant implications.

\subsection{MELBOURNE'S METROPOLITAN PLANNING}

Although "town and country planning" began in England during the nineteenth century, and although during the same period Australia adopted a British style public administration system, Anglophone city planning was late coming to Melbourne. Nevertheless, a replica of London's "Board of Works" was set up in late nineteenth century Melbourne to tackle the major problem of the day - sewerage disposal.

The cleansing of London in the 1880's had been one of the great civic achievements of its time, and the results achieved within “smelly" Melbourne during the 1890's were no less spectacular. To this day Melbourne has a vast network of underground sewerage tunnels that flow into a huge, open-air treatment facility located on its south western fringe. This sewerage farm still attracts hundreds of the world's municipal engineers who are keen to copy it - provided they can find so much space in their own localities.

It is therefore hardly surprising that the "Melbourne and Metropolitan Board of Works" (MMBW) wielded so much power for so long. Its annual right to extract a "metropolitan improvement rate" from virtually every property owner across the metropolitan area was enshrined within the legislation of the state of Victoria. Moreover, even though in the late twentieth century MMBW was dismantled, and partially privatized, to survive only as the much weakened "Melbourne Water", this institution was for a long time expected to control Melbourne land use patterns as a matter of course - especially since all property owners also had to also pay the MMBW a "metropolitan improvement rate", which was specifically earmarked for the acquisition and maintenance of public space, and "planning".

Nevertheless, the MMBW's land use planning always laboured under at least two major handicaps. Firstly, it was the local councils, of which there were, traditionally, 56 across the Melbourne metropolitan area, who often determined how the land would be used. These councils had their own zoning plans, which were supposed to mesh with the broad zones of the MMBW's metropolitan planning scheme but which frequently did not. That is, at a plot-by-plot level, most 
development control was carried out by the local authority rather than by the metropolitan authority.

Secondly, even at the broad, metropolitan scale, the historic nature of the MMBW meant that it was water engineers and not town planners who mostly determined the direction in which the suburbs would spread. The 200 or so planners on the fifth and sixth floors of the MMBW building could talk all they liked about how to manipulate Melbourne's pattern of land uses, but it was the 7000 or so engineers, higher up on the upper floors, who had the actual power to control urban morphology.

More exactly, unless the engineers' "preferred development areas" - a euphemism for areas that were cheaper to service with water reticulation, corresponded to the planners' zones for future residential development, the planners' plans never came to fruition. It was water engineers who were determining where and when Melbourne should grow, just like the Sydney Water Board's engineers for many years determined the shape of Sydney despite the best efforts of its urban planners. This meant that planners in Melbourne and elsewhere became very frustrated, which partly explains their behaviour, as covered in the next sub-section.

\subsection{MONKEYING WITH MORPHOLOGY}

Urban problems have usually prompted the same traditional response from Melbourne's metropolitan planners - a response that John Patterson (1979) so famously labelled "monkeying with morphology". That is, they always suggested new alterations to the layout, or spatial morphology of the Melbourne metropolitan area to somehow alleviate the city's problems and generally increase its citizens' quality of life. Put differently, Melbourne's planners have always been keen to propose a number of alternative land use patterns for taming the expanding, polluting monster that Melbourne has always shown signs of becoming.

This is illustrated in an early MMBW report (1967) where several alternative layouts for Melbourne were canvassed, some of which are shown in Figure 1. Shown in red is the existing built up area; the yellow indicates where extra development is to take place over the next twenty years, and green designates "open space".

On the top left the intention is service Melbourne's existing spatial pattern of growth, and on the top right the aim is to push much new development towards the less popular northern and western areas. In the middle is a proposal to banish much of Melbourne's new development to satellite towns that would be located beyond a partial green belt and which would emulate the English "new towns" of the post World War 2 era. Finally, the two scenarios along the bottom of Figure 1 show two kinds of "corridor growth plus green wedges of open space between corridors to act as the fresh air-providing 'lungs' of the city". The pattern on the bottom left involves expansion along major transport arteries, and on the bottom right is shown a plan to have expansion within planned "sectors" in order to fit in with the American geographer, Homer Hoyt's "sector theory".

This report was followed by a statement of planning policy (MMBW, 1971) in which some version of the "corridors with green wedges" layout was recommended as a blueprint for future Melbourne and public responses were invited. Something like 4000 such responses were received, and they were subsequently dealt with in a further report (MMBW, 1974). 


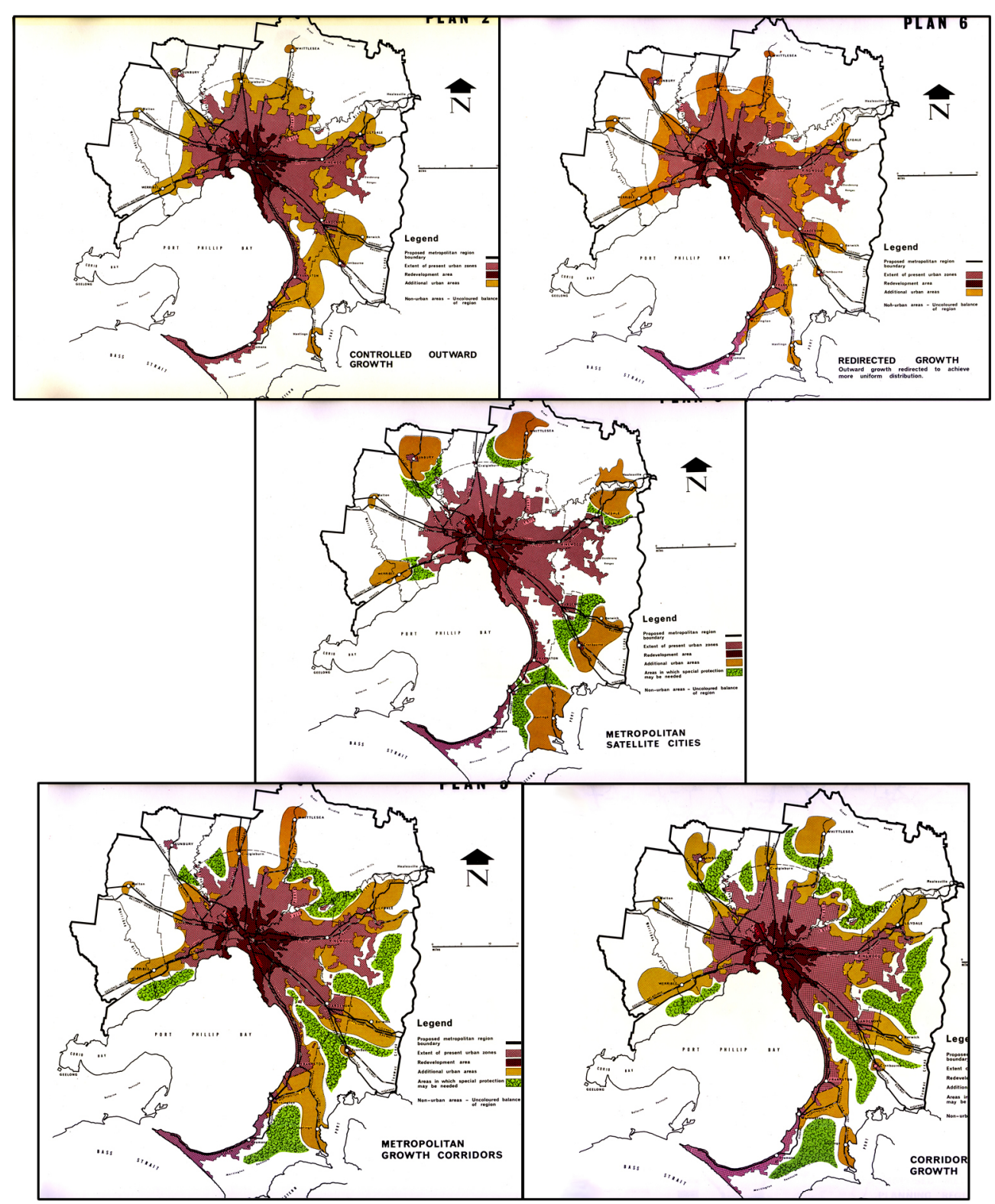

Figure 1 Some alternative urban morphologies considered in the MMBW's 1967 report on the "Future Growth of Melbourne"

Note that there was some doubt about how well citizens' responses were summarized, and some well known ones were simply ignored, such the one by urban activists Ruth and Maurie Crow (1972) which called for greater citizen participation in the planning process. The latter authors did not help their cause very much when their reports' inside covers stated that they had been printed by the Australian Communist Party. Given that the cold war was at the time a major issue in the minds of many, including politicians and government bureaucrats, this hardly 
tended to curry favour within the corridors of power. The planning process simply proceed as always, slowly and in a non-radical and measured way.

Yet even the conservative metropolitan plan began to be amended almost straight away, as various interest groups applied for, and were granted assorted local variations to it. By 1981 there were 151 amendments, and by today there have been hundreds more. This begs the question of how many amendments does it take before a plan can no longer be regarded as a plan at all. Clearly, Melbourne's metropolitan planning system was fairly weak.

Such weakness is often overlooked by outside researchers who read "official" documents claiming that public plans have genuine legislative "teeth". By contrast, local participants in the planning process realize otherwise. Apart from the difficulty of ever achieving draconian land use control within any liberal democracy, there are other, more subtle reasons why any Australian metropolitan plan is bound to be fairly ineffectual.

Firstly, urban planning tends to lack credibility because whenever a set of alternative "scenarios" for future growth are evaluated, such evaluation is never scientific. This is not because the planners in Melbourne are necessarily lazy or prejudiced against an empirical, scientific approach. It is just that the state of the (planning) art can never transform itself into a rigorous science. One can hardly run a controlled laboratory experiment in order to test each alternative plan's desirability, because planning scenarios are things that take more than a generation to evolve and they always exist only in the real world. Nor can one compare proposed scenarios with different plans that have been tried elsewhere, because like everywhere else Melbourne has its own unique features, which make it impossible to rigorously and comprehensively envisage what each blueprint for its future would actually be like to live in.

Put differently, whether or not one prefers a sprawling, or a dense or a corridor-based city tends to be based on subjective judgment stemming from prejudices about the intrinsic worth of sprawling cities, compact settlements, corridors and so forth. Worse, in Melbourne such judgments have become not only polarized but also politicized. On the one hand the MMBW supported its corridors/green wedges plan on the grounds that it was balanced and practical and it fitted neatly into an expanded MMBW region. On the other, an eastern regional growth plan was supported by those planners who worked for the state of Victoria (Town and Country Planning Board, 1967), partly because such a layout allowed metropolitan Melbourne to expand eastwards into areas controlled by state government bureaucrats, thereby depriving the MMBW of some of its political power.

This battle between rival institutions waged for some years, with the ascendancy usually going to the MMBW, and so the eastern regional alternative faded from the stage of genuinely viable plans. However, MMBW's attitude in favour of its own corridors/green wedges plan gradually began to morph into something else. The latter can be seen emerging within many MMBW reports (MMBW 1979a, 1979b, 1981; Little, 1977; Little and Carter, 1979) and since MMBW's fall from grace the same idea has been advocated within state planners' reports (Ministry for Planning and Environment, 1986; 1987; 1994). In such documents it is always argued that any plan's dominant thrust should be towards the containment of suburban sprawl.

Moreover, such a policy persists to this day (Department of Sustainability and Environment, 2005). It involves placing a barrier around Melbourne's suburban expansion and encouraging residents onto public transport by having relatively more of them living within walking distance from suburban "hot spots". The latter are meant to comprise denser and more mixed property 
development; they are now called "activity centres"; they should contain shops, offices and medium- to high-density housing, and they should straddle some form of transport exchange that is linked to other activity centres via the public transit system.

Yet this policy has almost always been a spectacular failure. This might be because, just like the former MMBW water engineers did, property developers now control much of Melbourne's metropolitan planning. It is in the financial interest of such developers to be allowed to build higher-density housing not only within activity centres but also across suburbia in general, and in their attempt to contain sprawl, planners have granted the developers this permission. Hence building companies have often lost interest in making activity centres work; it is more lucrative for them to erect dual-occupancy housing on formerly single-dwelling allotments almost everywhere.

Yet unlike what the city planners had hoped for, such suburban "densification" has generated mostly high-price housing for wealthy singles, empty nesters and retirees. This has meant that poor families, for whom a consolidated city was supposed to provide more affordable housing, have been forced to locate at the cheaper metropolitan periphery where they are more remote from city facilities than ever. In short, property developers continue to make money while planners agonize over why their policy has not brought all classes of people into the middle suburbs to make Melbourne a more densely settled and socially diverse place.

It is true that much of the torpedoing of Melbourne's land use planning has been at the hands of resident action groups from the green and leafy eastern suburbs, such as the "Save our Suburbs" (SOS) organization. These have managed to stop many higher-density development initiatives within their neighbourhoods, whether such developments were proposed as part of a designated activity centre or not. But whatever the explanation, it seems fairly certain that Melbourne's urban planners monkeying with morphology has had a lot less impact than official government documents would suggest.

\subsection{BALANCED AND CONTROLLED GROWTH}

For example, a major problem that has distressed Melbourne's planners and others for decades is the city's tendency to grow towards the south and east rather than towards the less hospitable north and west. To the government planners it simply did not feel right that Melboune's CBD was, and is still becoming increasingly off centre - most cities have their CBD roughly in the middle. Nor was this welcomed by the large retailers as their city department stores became increasingly more remote from the vast swathes of southern and eastern suburbia.

However, many such retailers overcame this problem by building large, stand alone, drivein shopping centre complexes or hypermarkets, often in defiance of the metropolitan plan which wanted such developments only within activity centres but which was relatively powerless to stop them. In fact, planners frequently even allowed such centres to be built close to strip shopping centres, thereby taking away their trade and causing them to decline, even though the planners had sometimes designated such strips to be future activity centres.

In short, planning policy within Melbourne today is full of compromises. One only has to look at the pattern of land releases being advocated by VicPlan, by the Urban Development Authority before it, and by the various public growth-management authorities before that, to see that they were all trying to have a "little each way". For example, on the one hand an emphasis on "north west stimulation" is still very much in evidence, with far greater hectares of 
new residential land being earmarked for release in such areas. Yet on the other hand there has always been a concession to the reality that the south eastern, Berwick corridor will continue to be Melbourne's fastest growing area, and so some land releases have always been planned for that region as well.

Hence no matter how much talk about limiting sprawl exists within the current State government's Melbourne 2030 report (Department of Sustainability and Environment, 2005), as indeed there has been in so many previous publications, there endures an acknowledgement that Melbourne will continue to sprawl in the "wrong" direction", just as the private sector controllers of growth want it to.

Moreover, some argue that VicPlan has been diverted towards servicing the demands of private developers within the massive, central city Docklands project, causing it to even temporarily lose sight of its traditional advocacy for more northern and western sprawl. Such diversion is always justified on the grounds that inner-area growth will make Melbourne more compact and easier to service, yet in so doing, the planners have let down the less wealthy residents yet again.

As already noted, poorer people are being increasingly forced out of accessible areas and closer to the cheaper but ever more distant outskirts of the metropolis, where public transport is scarce or even nonexistent, forcing dual car ownership and hardship. Worse, they are now being made to live at far higher densities than their predecessors, given the penchant for governments to allow the private sector to develop huge suburban estates themselves in order to save the government money. Mega developers work to a "bottom line" whose health will only be acceptable to their accountants when ordinary people's living densities are made higher than those traditionally enjoyed within the world's most liveable city.

Meanwhile, the planners continue to justify such corporate greed on the vaguest of grounds, which they tend to label with nebulous terms like "sustainability" - compact, self-contained, private housing estates on the city fringes are supposed to be more environmentally friendly. Such justifications have not, and probably can never be properly tested for validity. But this does not stop both private and public authorities from mouthing them incessantly.

Hopefully, some of the papers in the theme issue will help readers to appreciate the facts more clearly, and to see through some of the double talk that has always characterised Melbourne's metropolitan planning. If so, "public" understanding will be raised by a small amount and this, although never definitive, is the only thing that will re-shape government spending priorities to resist dominance by vested interest groups who, for too long, have claimed that their profitmaking is actually in the public interest.

\subsection{THE THEME ISSUE'S MESSAGES}

As an example of increased insight, note the paper by Tsutsumi and O'connor. It highlights the strong building activity that is currently occurring within the Melbourne CBD and which is being stimulated by growing demands for accommodation and property ownership by overseas students and their benefactors. Such stimulation of the central area certainly seems to have come at an opportune time. The flight from Melbourne of many company headquarters to its traditional rival - Sydney, a metropolis that has recently forged ahead in terms of population growth and attainment of "world city" status - could have led to property decline in Melbourne's centre. But it has not, thanks to the tertiary education sector. 
It is also true that such inner-area growth happens to match the developers' and planners' rhetoric that a more concentrated city is more environmentally and economically sustainable. Yet it is probably impossible to fully test whether or not such inner-city densification is environmentally superior, and it may not be economically sustainable at all. Hence although this innercity boom has been fortuitous and beneficial, it should on no account lead to complacency. Perhaps capital from overseas needs ultimately to be supplemented from other sources.

Yet such a cautionary note may be too pessimistic. Tsutsumi and O'Connor also imply, without suggesting it directly, that the continued growth of Melbourne's CBD employment in the "finance and insurance" sector is actually due to residential apartments being built behind the street frontages in order to subsidize the creation of office facilities within older and more visible "heritage" façades.

However, it seems debatable that such development is being propped up by the real estate industry in this way. Something more permanent might be at work. For instance, it could be that the Melbourne CBD job market is strong because of the opportunities provided through the city being a leader within the information technology, health care, education and medical research sectors. Add to this its cooler climate, parklands, manageable size, general comfort and more "refined" environment compared to some other Australian cities, and it begins to appear that Melbourne's central area possesses a strong base for continued prosperity well into the future. Time will tell.

Nevertheless, the paper by Yamashita, Fujii and Itoh, on suburban shopping centres, reinforces this optimistic tone. These authors' view of the beneficial effects of planning within metropolitan Melbourne is far more charitable than the opinions expressed above. They point out that not only has Melbourne's CBD remained much more economically healthy than CBDs within many US cities, but small-scale shops have also flourished in Melbourne's suburban centres better than they have in places like USA, Japan and Canada. To them, this is mostly due to Melbourne's policy of boosting "district centres" and "activity centres" since the 1980's. Where the latter occur, they often contain a mix of functions, which postpones the day when Melbourne succumbs to the Los Angeles type of "big box" centre. Each of the latter tries to be a mini-city in itself, yet each one further dilutes the coherent retailing fabric of the metropolis.

However, centres like Moonie Ponds and Glen Waverly, which Yamashita, Fujii and Itoh survey in detail and generally praise, may not actually be carrying the future with them, because if visitor numbers were accessed we would probably find that the larger battle is being lost. That is, it is probable that more and more people are being attracted to car-based, stand-alone hypermarkets rather than to public transit-oriented activity centres. In this sense, although Melbourne's planners may have staved off the inevitable for now, the suburban environment is probably creeping towards Americanization all the same. As these authors suggest, more research, particularly in the form of user surveys, is required.

The paper by Ishikawa and Tsutsumi conveys a similar message, even though it is not about Melbourne at all. Their paper is about Dallas, USA, which displays many of the characteristics that Melbourne will acquire if some of its current trends continue unchecked - like neglect of its public transport system. Although Melbourne is not as large as Dallas-Fort Worth, and although it has a more coherent network of suburban shopping centres, and despite the segregation of its non English-speaking migrants being not so extreme, car-based cross-suburban commuting in Melbourne is on the rise and its public transport patronage is falling. 
Ishikawa and Tsutsumi go on to describe, in some detail, the modest success that some new rail facilities within Dallas have had in terms of boosting the extent and variety of activities near its stations, not to mention their revitalizing of parts of Dallas' long defunct downtown area. Yet two things should be kept in mind. Firstly, these new rail initiatives have to a great extent simply serviced changes to the city that had already happened in the private enterprise-led fashion of American urban development. Secondly, public transport usage in Dallas is still declining.

Although the authors are hopeful that the proportion of people using transit will rise once the full transit network becomes operational in Dallas by 2007, their paper tends to suggest that it is very difficult for new, fixed-rail facilities to service everyone. Today's residents in Dallas, Melbourne or wherever, demand flexibility, which is why the motor car continues to dominate. Hence breaking car dependence within any city, even in those where urban planners have had some small successes, continues to be a very daunting task.

The paper by Fujii, Yamashita and Itoh echoes this when it comprehensively compares commuter flows within Atlanta and Melbourne. Once again, Melbourne's strong CBD and more self-contained suburban activity centres are highlighted, yet the authors point out that there is still considerable cross-suburban commuting in Melbourne. Moreover, such within-suburb commuting is usually serviced by private car rather than by public transport, due to the demands for flexibility from such groups as two-income households.

In other words, their paper carefully presents both the good and the bad. It details the economic and social strength of Melbourne's inner areas and how up to $50 \%$ of commuters into the CBD use public transport. Yet on the other hand, there are far more jobs in Melbourne's suburbs than in its central city, and commuting to these suburban jobs is every bit as car dependent as it is anywhere in the US. Moreover, although the planner-induced and wider range of functions within Melbourne's suburban centres, compared to its American equivalents, will theoretically prompt greater self containment around them and so generate less suburban travel overall, they still lack the sheer scale of US "edge cities", and this actually makes them less of a magnet for localized travel.

The overall impression left by our visiting scholars then, apart from their slightly greater appreciation of the achievements of Melbourne's urban planners, is that car dependence is a major and growing problem. This is why the fifth paper, written by one of the editors, takes up this theme.

It argues that a large portion of the 478,000 jobs within Melbourne's inner areas are commuted to, by car, from the suburbs, each day. Such cars clog up inner-area roads and slow down street trams to the point of discouraging even locals from using them. This causes higher peak-hour air pollution, heavy wastage of fossil fuels and a massive annual economic bill for congestion. Moreover, although the growing car dependence problem has existed for at least 50 years, remarkably little progress has been made in terms of solving it.

Accordingly, this paper uses GIS to explore a completely untried and technical solution, which contrasts with traditional land use pattern-oriented solutions - Personal Rapid Transit. This is such a radical proposal that few people are likely to be convinced of its efficacy, yet the author tries to show that at least it ought to be experimented with, albeit in a way that exploits Melbourne's present transport infrastructure rather than competes against it.

Overall, we hope that the analyses and discussions in this theme issue will prove beneficial to everyone who seeks greater urban knowledge and insight. If so, readers will reach better and 
more GIS-informed conclusions about how urban planners within their own city can improve their urban environment.

\author{
Jun Tsutsumi and Ray Wyatt \\ Melbourne, \\ August 2006
}

\title{
REFERENCES
}

Crow, R.; Crow, M. 1972. Plan for Melbourne: Part 3. Melbourne: Victorian State Committee of the Communist Party of Australia.

Department of Sustainability and Environment. 2005. Melbourne 2030, Melbourne. Available from: http://www.dse.vic.gov.au/melbourne2030online/content/introduction/02summary.html.

Little, F.M. 1977. Socio-economic implications of urban development. Melbourne: Urban Economic Consultants Pty Ltd and MMBW.

Little, F.M.; Carter, R.A. 1979. Urban development economic development and growth. Melbourne. Urban Economic Consultants Pty Ltd and MMBW.

Ministry for Planning and Environment. 1986. Pilot study of urban consolidation policy and its application to metropolitan Melbourne. Melbourne: Travers Morgan Pty Ltd.

Ministry for Planning and Environment. 1987. Shaping Melbourne's future. Melbourne.

Ministry for Planning and Environment. 1994. Melbourne metropolitan strategy. Melbourne.

Melbourne and Metropolitan Board of Works. 1967. The future growth of Melbourne. Melbourne.

Melbourne and Metropolitan Board of Works. 1971. Planning policies for the Melbourne metropolitan region. Melbourne.

Melbourne and Metropolitan Board of Works. 1974. Report on general concept objections. Melbourne.

Melbourne and Metropolitan Board of Works. 1979a. Alternative strategies for metropolitan Melbourne. Melbourne.

Melbourne and Metropolitan Board of Works. 1979b. The challenge of change. Melbourne.

Melbourne and Metropolitan Board of Works. 1981. Metropolitan strategy implementation. Melbourne.

Patterson, J. 1979. Melbourne and metropolitan: Monkeying with morphology (again) (?) in Proceedings and Papers of the Melbourne Metropolitan Planning Options Forum. Melbourne: Department of Town and regional Planning. University of Melbourne. 78-83.

Town and Country Planning Board of Victoria. 1967. Organization for strategic planning. Melbourne.

Cite this article as: Tsutsumi, Jun; Wyatt, Ray. 2006. 'A brief history of metropolitan planning in Melbourne, Australia'. Applied GIS 2 (2). pp. 7.1-7.10. DOI: 10.2104/ag060007. 